\title{
DESEMPENHO REPRODUTIVO DE OVELHAS ALIMENTADAS COM DIETAS CONTENDO DIFERENTES NÍVEIS DE ENERGIA NO TERÇO INICIAL DA PRENHEZ
}

\author{
Filipe Gomes de Macedo ${ }^{1}$, Gentil Vanini Moraes², Natália Holtz Alves Pedroso \\ Mora $^{2}$, Francisco de Assis Fonseca de Macedo², Elias Nunes Martins ${ }^{2}$, Franciane \\ Barbiéri Dias-Senegalhe ${ }^{3}$
}

\author{
1 UNESP \\ 2 UEM \\ 3 UFGD \\ Correspondência: Filipe Gomes de Macedo: fgm_vet@hotmail.com
}

RESUMO: Após a sincronização de estro e cobertura, 120 fêmeas Santa Inês foram distribuídas em quatro tratamentos de Nutrientes Digestíveis Totais (NDT): 59,68\%; 66,28\%; 72,93\%; e 79,39\%, utilizando-se ração total, de 0 a 50 dias de gestação, para avaliar o índice de prenhez em função dos níveis energéticos da dieta e da taxa de glicose circulante, bem como a absorção embrionária em função da condição corporal (CC) e da taxa de glicose circulante no momento da cobertura. No dia da cobertura e a cada dez dias, foram coletados $5 \mathrm{~mL}$ de sangue para determinação imediata do teor de glicose e para dosar a progesterona circulante. A partir do $25^{\circ}$ dia pós-cobertura, realizaram-se exames de ultrassonografia, para acompanhamento da gestação, visando avaliar perdas embrionárias. A taxa de perda embrionária foi correlacionada com os níveis energéticos das dietas e com os níveis de glicose circulante e, antes dos 20 dias, utilizaram-se os níveis sanguíneos de progesterona para estimar a prenhez. As fêmeas que apresentaram valores de progesterona acima de $1 \mathrm{ng} / \mathrm{mL}$ de plasma foram consideradas prenhas aos 20 dias. A mortalidade embrionária não foi influenciada $(P>0,05)$ pela taxa de glicose circulante das ovelhas, no dia da cobertura. A taxa de prenhez foi influenciada $(P<0,05)$ pela $C C$ das fêmeas no dia da cobertura, com maior índice de prenhez nas ovelhas com $\mathrm{CC}=3$. A glicose diminuiu com o aumento do peso e da $\mathrm{CC}$, com as ovelhas mais pesadas e em melhor CC, apresentando maior probabilidade de mortalidade embrionária. Houve ganho de peso linear das ovelhas, de 0 a 50 dias pós-cobertura, em função do aumento dos níveis de energia da dieta. Recomenda-se cobrir ovelhas com maior taxa de glicose circulante, CC próxima a três e dieta com $59,68 \%$ de NDT, nos primeiros 50 dias de gestação.

Palavras-chave: condição corporal; glicose; mortalidade embrionária; prenhez; progesterona

\section{REPRODUCTIVE PERFORMANCE OF EWES FED WITH DIETS CONTAINING DIFFERENT LEVELS OF ENERGY IN THE EARLY PREGNANCY}

\begin{abstract}
After estrus synchronization and breeding, 120 Santa Inês ewes, were distributed in four treatments Total Digestible Nutrients (TDN): 59.68\%; 66.28\%; 72.93\%; and 79.39\%., using total feed, from 0 to 50 days of pregnancy, to evaluate the pregnancy rate in function of the levels of energy in diet and glucose, as well as embryo loss in function of body condition (BC) and glucose level. On breeding day and for each 10 days, five $\mathrm{mL}$ of blood sample were collected to immediate determination of glucose and to dose progesterone. From $25^{\circ}$ day after breeding, ultra-sound exams were realized, to pregnancy accompaniment, to evaluate embryo loss. The embryo loss rate was correlated with the energy levels of the treatments and glucose level and, before the day 20, the pregnancy was confirmed by the blood progesterone level. The female that had more than one $\mathrm{ng} / \mathrm{mL}$ were considered pregnant at day 20. The embryo loss were not affected $(P>0.05)$ by the glucose rate in the ewes on the day of breeding. The pregnant rate were not affected $(P<0.05)$ by $B C$ of the ewes in the moment of breeding, with a higher rate of pregnancy to the ewes with $\mathrm{BC}=3$. The glucose gets low with the weight and BC gain, with the heavy ewes and in better BC with high probability of embryo loss. There was a linear weigh gain in the ewes, from 0 to 50 days after breeding, in function of the increase in energy feed level. It's recommended to breed ewes with a higher glucose rate, BC near to three points and diet with $59.68 \%$ TDN, in the 50 first days of pregnancy.
\end{abstract}

Key Words: body condition; embryo loss; glucose; pregnancy; progesterone 


\section{INTRODUÇÃO}

Ovelhas Santa Inês ciclam durante o ano todo, em sua região de origem, no Nordeste Brasileiro, e na região Sudeste (SASA et al., 2002), caracterizando-se como poliéstricas anuais, 0 que possibilita a realização de mais de uma estação de monta ao ano, na busca de três parições a cada dois anos. Além disto, a taxa de prolificidade é de 1,19 e a produção de leite é boa (CORREIA NETO et al., 2006), sobrepondo-se às raças lanadas, que são influenciadas pelo fotoperíodo, reduzindo seu desempenho em relação às deslanadas. Assim, as ovelhas deslanadas podem ser utilizadas como ventres para a produção de cordeiros destinados ao abate, bem como receptoras em programas de transferência de embriões.

O desempenho produtivo dos animais é fortemente influenciado dentre outros fatores, pelo ambiente, nutrição e a consequente condição corporal, estado de saúde, manejo reprodutivo e genética (SIMPLÍCIO et al., 2007). Em ovelhas, a fertilidade, a prolificidade e a sobrevivência dos cordeiros demonstram a eficiência reprodutiva, em que a prolificidade se deve à taxa de ovulação natural, a qual pode ser modificada pela nutrição (CEZAR \& SOUSA, 2006).

Em estudos pioneiros, já foi observado que o efeito da subnutrição ou da supernutrição energética de ovelhas no início da gestação têm mostrado a ocorrência de perdas embrionárias (EDEY, 1976; PARR E CUMMING, 1982). A energia é o nutriente mais importante na relação entre a nutrição e desempenho reprodutivo das ovelhas, sendo que uma eficiente utilização dos alimentos pelos animais depende de um suprimento adequado de energia, pois a sua deficiência reduz a fertilidade (RESENDE et al. 2001). Uma forma de melhora da nutrição antes e durante a monta seria o flushing, alimentação suplementar energética que tem como objetivo aumentar o peso e a condição corporal para melhorar o desempenho reprodutivo das fêmeas. Menzies et al. (1998) encontraram menor mortalidade embrionária em fêmeas que respondiam ao flushing e possuiam boa condição corporal.

Diante disso, o estudo foi realizado com o objetivo de avaliar o índice de prenhez em função dos níveis energéticos da dieta no início da gestação e da taxa de glicose circulante, bem como a perda embrionária em função da condição corporal e da taxa de glicose circulante, em ovelhas Santa Inês.

\section{MATERIAL E MÉTODOS}

O experimento foi desenvolvido, de junho a setembro de 2008, na Universidade Estadual de Maringá. Foram selecionadas 120 ovelhas da raça Santa Inês, as quais, nos primeiros 21 dias do experimento tiveram acesso a solários, recebendo ração completa com 11,73\% de Proteína Bruta (PB) e $72,93 \%$ de Nutrientes Digestíveis Totais (NDT), perfazendo $110 \%$ das exigências em NDT (NRC, 2007), para promoção do flushing alimentar.

No oitavo dia do período préexperimental, iniciou-se a sincronização do estro das ovelhas, com dispositivo intravaginal de $60 \mathrm{mg}$ de acetato de medroxiprogesterona (MAP) e, no quinto dia da colocação do pessário com MAP foi aplicado, via intramuscular, $0,5 \mathrm{~mL}$ de agente luteolítico $(0,1325 \mathrm{mg}$ de Cloprostenol sódico). No $11^{\circ}$ dia os pessários foram retirados e foram administrados $1,5 \mathrm{~mL}$ de Gonadotrofina Coriônica Equina - eCG (300 UI). Nos dias 12 e 13 do protocolo, as ovelhas foram cobertas por carneiros de cinco raças diferentes, dois reprodutores de cada raça (Santa Inês, Dorper, Texel, lle 
de France e Hampshire Down), com fertilidade estimada mediante exame andrológico.

Após a cobertura, as 120 fêmeas foram distribuídas conforme peso (média de 43,1 kg) e idade (de 1,5 a 3 anos), em quatro tratamentos, utilizando-se ração total, com variação apenas dos níveis de energia no terço inicial de gestação (até 50 dias póscobertura). Os níveis de energia das dietas experimentais foram de 90; 100; 110; e 120\% da exigência de mantença em NDT para o terço inicial da gestação de ovelhas (NRC, 2007), demonstrados na Tabela 1.

Após as coberturas, as ovelhas identificadas de acordo com cada tratamento foram mantidas em instalações cobertas ( $2 \mathrm{~m}^{2} /$ ovelha), com piso ripado suspenso, onde tiveram acesso aos respectivos tratamentos nutricionais e a uma mistura de sal mineral específico para a espécie, ad libitum. As ovelhas permaneceram nas instalações, tendo acesso apenas a um solário, das $10 \mathrm{~h}$ às $15 \mathrm{~h}$, diariamente, para controle da ingestão da dieta. A dieta fornecida por dia foi fracionada em duas partes iguais, sendo fornecida às $8 \mathrm{~h} 30 \mathrm{~min}$ e às $16 \mathrm{~h} 00 \mathrm{~min}$, diariamente, perfazendo $100 \%$ do fornecimento/animal/dia.

\begin{tabular}{|c|c|c|c|c|}
\hline \multirow[b]{2}{*}{ Itens } & \multicolumn{4}{|c|}{ NDT $(\%)$} \\
\hline & 90 & 100 & 110 & 120 \\
\hline Feno Coast-cross & 63,06 & 60,73 & 50,77 & 57,06 \\
\hline Casca de Soja & 20,0 & 20,0 & 20,0 & 20,0 \\
\hline Farelo de Soja & 12,02 & 9,17 & 6,75 & 4,7 \\
\hline Milho Grão & 4,92 & 10,1 & 14,48 & 18,24 \\
\hline \multicolumn{5}{|c|}{ Composição Química } \\
\hline Matéria Seca & 87,3 & 87,27 & 87,43 & 87,55 \\
\hline Proteína Bruta & $9,82\left(10,8^{1}\right)$ & $9,72\left(11,66^{2}\right)$ & $9,02\left(11,73^{3}\right)$ & $9,2\left(12,88^{4}\right)$ \\
\hline $\mathrm{NDT}^{5}$ & $54,25\left(59,68^{1}\right)$ & $55,23\left(66,28^{2}\right)$ & $56,1\left(72,93^{3}\right)$ & $56,71\left(79,39^{4}\right)$ \\
\hline FDN & $62,36\left(68,6^{1}\right)$ & $60,57\left(72,68^{2}\right)$ & $58,96\left(76,65^{5}\right)$ & $57,6\left(80,64^{4}\right)$ \\
\hline FDA & $38,27\left(42,1^{1}\right)$ & $36,33\left(43,6^{2}\right)$ & $34,68\left(45,08^{3}\right)$ & $33,2\left(46,48^{4}\right)$ \\
\hline Extrato Etéreo & $1,29\left(1,42^{1}\right)$ & $1,44\left(1,73^{2}\right)$ & $1,57\left(2,04^{3}\right)$ & $1,68\left(2,35^{4}\right)$ \\
\hline Matéria Mineral & $3,9\left(4,29^{1}\right)$ & $3,74\left(4,49^{2}\right)$ & $3,61\left(4,69^{5}\right)$ & $3,49\left(4,89^{4}\right)$ \\
\hline
\end{tabular}

No dia da cobertura e a cada dez dias, durante o terço inicial de gestação, foram coletados $5 \mathrm{~mL}$ de sangue, previamente ao fornecimento da dieta, via venopunção da jugular, utilizando-se agulhas descartáveis de $40 \times 12$, para determinar o teor imediato de glicose $(\mathrm{ng} / \mathrm{mL})$ com o kit próprio e também para quantificar, posteriormente, a progesterona circulante.

Para a quantificação do teor de progesterona, o sangue foi depositado em tubos de ensaio estéreis. Imediatamente após a colheita sanguínea, os tubos de ensaio foram acondicionados em recipiente de isopor contendo gelo. As mesmas foram conduzidas ao laboratório e foram centrifugadas a $4.583 \mathrm{~g}$ por $10 \mathrm{~min}$ e, o plasma, separado e acondicionado em tubos de $2 \mathrm{~mL}$, os quais foram congelados a $-20^{\circ} \mathrm{C}$.

Ao término da fase de colheita de dados e amostras, os tubos de $2 \mathrm{~mL}$ congelados, contendo as amostras de plasma sanguíneo, foram encaminhados para o Laboratório de Endocrinologia Animal da Universidade Estadual Paulista "Júlio de Mesquita Filho" (UNESP), campus de Araçatuba, para determinar a concentração de progesterona pelo método de radioimunoensaio ( $\mathrm{RIE}$ ).

A partir do $25^{\circ}$ dia pós-cobertura, realizaram-se exames de ultrassonografia, com transdutor linear retal e frequência de $5,0 \mathrm{MHz}$, com intervalo de cinco dias, para acompanhamento da gestação, visando avaliar perdas embrionárias. Os exames foram repetidos até os 50 dias póscobertura das fêmeas.

A taxa de perdas embrionária foi correlacionada com os níveis energéticos das dietas e os níveis de glicose circulante e, antes dos 20 dias, utilizaram-se os níveis sanguíneos de progesterona para estimar a prenhez. As fêmeas que apresentaram valores de progesterona acima de $1 \mathrm{ng} / \mathrm{mL}$ foram consideradas prenhas aos 20 dias 
(Ramim et al., 2007). Os coeficientes de variação inter e intra-análise foram $0,5 \mathrm{e}$ $0,6 \%$, respectivamente.

Os dados coletados foram analisados por meio de modelos de regressão polinomial, em nível de $5 \%$ de significância. As informações de glicose circulante no dia Zero foram analisadas alternativamente em função do peso ou da condição corporal da ovelha à cobertura, usando modelos lineares clássicos.

As informações de taxa de prenhez e absorção embrionária foram analisadas, respectivamente, em função da condição corporal e da glicose circulante à cobertura, empregando-se a metodologia de modelos lineares generalizados, assumindo-se a distribuição binomial e a função de ligação Logit. Da mesma forma, a variação do peso, da cobertura até 50 dias, foi analisada em função dos níveis energéticos da ração, usando a metodologia de modelos lineares generalizados, assumindo-se a distribuição gama com função de ligação recíproca. Como a variação de peso assumiu, em alguns casos, valores negativos para todas as observações dessa variável foi adicionada uma constante para viabilizar a adoção da distribuição gama na analise, dado que ela não admite valores nulos ou negativos.

\section{RESULTADOS E DISCUSSÃO}

$\mathrm{Na}$ Tabela 2, são observadas as taxas de prenhez aos 20 e aos 50 dias, absorção embrionária e os valores médios de progesterona para as ovelhas prenhas e vazias.

Apesar dos animais terem sido distribuídos de modo que o peso e a condição corporal fossem homogêneos, não houve homogeneidade quanto ao nível de glicose e, isso se deve ao comportamento individual dos animais. O valor variou de 40 a $90 \mathrm{ng} / \mathrm{mL}$, com maior frequência entre 40 a $80 \mathrm{ng} / \mathrm{mL}$ de sangue.

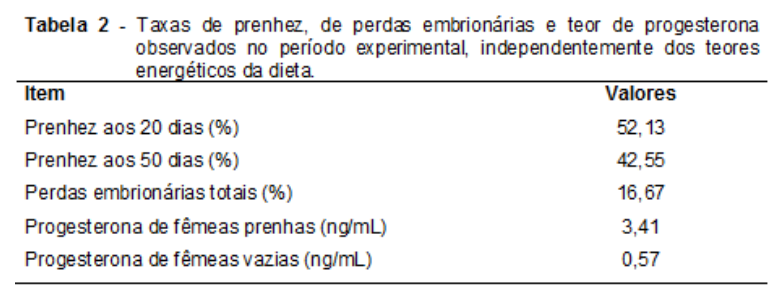

Em cabras sem raça definida, mantidas em fazendas, em bom estado nutricional e jejum de 8h, Araújo \& Silva (2008) observaram valores plasmáticos médios de glicose que variam de 31,9 a $64,7 \mathrm{ng} / \mathrm{mL}$ (média de 48,3 ng/mL). Com ovelhas adultas (50 kg de peso vivo), Rigolon et al. (1999) encontraram 27,66 ng de glicose $/ \mathrm{mL}$ de plasma nas controles (mantidas em pastagens de Coast cross), 45, 45,87 e $38,86 \mathrm{ng} / \mathrm{mL}$ naquelas que receberam, via suplementação energética, 15,30 e $45 \%$ de energia metabolizável além da mantença, respectivamente.

A perda embrionária entre os 20 e 50 dias após a cobertura (Figura 1) não foi influenciada $(P>0,05)$ pela taxa de glicose no dia da cobertura.

Observa-se que a taxa de perdas

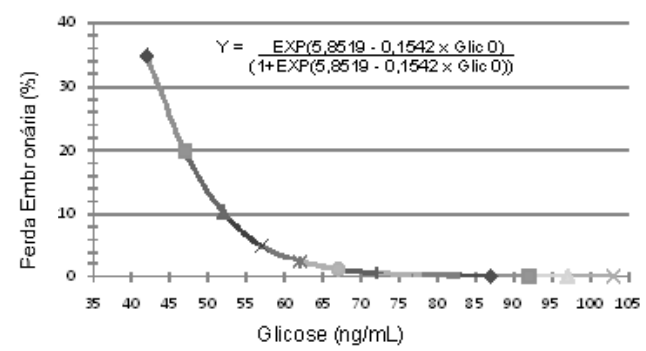

Figura 1 - Perdas embrionárias em ovelhas Santa Inês, em função da taxa de glicose sanguínea estimada ( $\mathrm{ng} / \mathrm{mL}$ ) no dia da cobertura analisadas quanto à prenhez, com ultrassom, a partir de 25 dias de cobertura.

embrionárias, que no experimento foi, em média, de $16,67 \%$, seguiu o mesmo comportamento em todos os tratamentos, diminuindo com o aumento dos níveis de glicose plasmática. Contrariamente, Rigolon et al. (1999) observaram aumento da glicose do grupo controle $(27,66 \mathrm{ng}$ de glicose $/ \mathrm{mL})$ até a adição de $27 \%$ de energia 
metabolizável em relação à mantença, seguido de um decréscimo do nível de glicose sanguínea, $35,86 \mathrm{ng} / \mathrm{mL}$ para 49 $\mathrm{ng} / \mathrm{mL}$ nas ovelhas que receberam $30 \mathrm{e}$ $15 \%$ de suplementação, respectivamente, e que de acordo com Rubio et al. (1997), essa redução se deve à elevação da insulina circulante.

Nos ruminantes, a glicose é utilizada como principal fonte energética pelo sistema nervoso, fígado, glândula mamária e rim, mas os tecidos fetais a utilizam como carboidrato básico para o seu desenvolvimento (ARAUJO e SILVA, 2008). Rubio et al. (1997) observaram que o nível sanguíneo de glicose, em ovelhas, não melhorou a performance reprodutiva. Rigolon et al. (1999) observaram que a redução do teor de glicose plasmática com a elevação dietética de energia não prejudicou a produção de embriões e, Ramim et al. (2007) notaram valores de glicose sanguínea altos em ovelhas que abortaram $(39,5 \mathrm{ng} / \mathrm{mL})$ e baixos em ovelhas gestantes $(31,8 \mathrm{ng} / \mathrm{mL})$. Já, Seidel et al. (2006) notaram certa hipoglicemia nas ovelhas gestantes, em especial nas portadoras de gêmeos.

Em ovelhas, há relação inversa entre estado nutricional após a cobertura e as concentrações periféricas de progesterona (WILLIAMS e CUMMING, 1982), nas quais baixas concentrações de progesterona após planos alimentares altamente energéticos têm sido associadas a perdas embrionárias.

As condições de hiperglicemia podem demonstrar a associação entre metabolismo embrionário, estresse e potencial de desenvolvimento futuro, em que uma elevação no metabolismo da glicose, particularmente via glicólise, pode ser vista como uma resposta do embrião ao estresse (LEESE, 2002).

Os embriões de ruminantes são dependentes da disponibilidade de substâncias nutritivas presentes no útero, decorrentes de adequada nutrição materna, especialmente a de glicose e oxigênio, para o seu desenvolvimento e sobrevivência (ASHWORTH, 1995). Esse mesmo autor observou, em ovelhas superalimentadas no início da gestação, redução de embriões produzidos. Acredita-se que isso seja resultante do aumento do metabolismo da progesterona, em consequência de uma elevação na atividade de oxidação hepática pelo maior fluxo sanguíneo porta-hepático em animais bem alimentados, já que o fígado é o principal local de metabolismo de esteróides. $\bigcirc$ fígado metaboliza aproximadamente $95 \%$ da progesterona circulante durante uma única passagem, resultando em uma redução das concentrações plasmáticas periféricas de progesterona. Assim, mudanças no consumo de nutrientes podem influenciar o metabolismo da progesterona, podendo ocasionar redução da mesma e, por consequência, impedir a manutenção de concentrações adequadas desse esteróide para garantir que os mecanismos luteolíticos sejam superados ou suprimidos.

Observa-se na Figura 2, que ao distribuir a probabilidade de prenhez em função da condição corporal (CC), a taxa de prenhez $(52,13 \%)$ aos 20 dias pós-cobertura, determinada pela quantificação de progesterona, foi influenciada pela $\mathrm{CC}$ das fêmeas ovinas no momento da cobertura, em que a maior taxa de prenhez ocorreu em ovelhas com $\mathrm{CC}$ igual a três pontos, diminuindo $(P<0,05)$ quando a $C C$ variou 0,5 pontos para mais ou para menos.

Recomenda-se acompanhamento criterioso no manejo alimentar das fêmeas ovinas, para que estas estejam com condição corporal o mais próximo possível de três pontos, no momento da cobertura, para que haja resposta 
eficiente na taxa de prenhez. Portanto, esse parâmetro deverá ser utilizado no preparo das fêmeas ovinas para serem cobertas, orientando da necessidade ou não da promoção do flushing alimentar. O comportamento apresentado orienta a utilização do flushing apenas em ovelhas com condição corporal entre 2 e 2,5 pontos e a manutenção da oferta de energia a partir da CC de 3 pontos, uma vez que as respostas causadas pelo efeito dinâmico negativo podem ser prejudiciais.

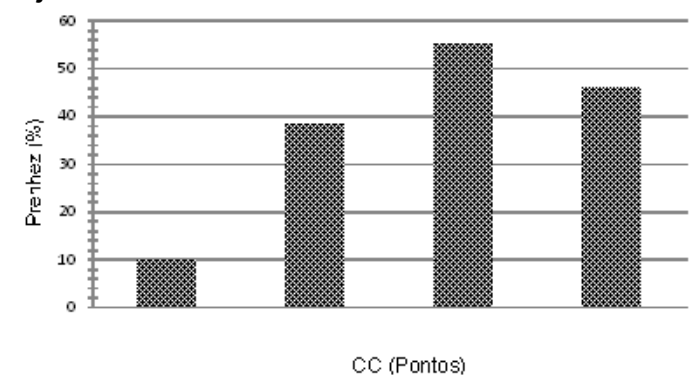

Figura 2 - Probabilidade de prenhez média de ovelhas Santa Inês em função da condição corporal (CC) no momento da cobertura.

De acordo com Cezar e Sousa (2006), durante o período de monta, a CC pode apresentar variações para mais ou para menos, como resultado do consumo de energia nesse próprio período, denominado efeito de curto prazo ou efeito dinâmico da energia sobre a reprodução. Se o consumo de energia for superior às suas necessidades, o animal fica em balanço energético positivo, a CC melhora e o efeito dessa dieta energética é tido como efeito dinâmico positivo. Se o consumo for inferior à demanda energética, o animal entra em balanço energético negativo, a CC piora e o efeito dessa dieta é denominado de efeito dinâmico negativo da energia sobre a performance reprodutiva.

Gunn e Maxwell (1989), avaliando o fornecimento de dietas energéticas de sub-mantença, com perda de CC, de mantença e outra de sobre-mantença, à ovelhas com baixa condição corporal, por cinco semanas antes da monta, observaram taxa de ovulação de 1,0; 1,2 ; e 1,4 , respectivamente; isto revela 0 efeito dinâmico positivo da energia em matrizes com baixa CC. Contrariamente, as ovelhas em boa condição corporal não aumentaram ou reduziram sua taxa de ovulação, quando foram submetidas às dietas de sub, sobre ou de mantença, mantendo-a mais ou menos constante e, em torno de 2,0, independente do nível de consumo energético. Portanto, as matrizes ovinas que apresentaram melhor eficiência reprodutiva foram as que estavam com CC de 2,0 a 2,5 pontos para serem suplementadas na pré-estação de monta, de modo que a alimentação de flushing, no decorrer desse período, resulte em melhoria da CC $e$, por conseguinte, aumente o desempenho das fêmeas durante a estação de monta.

\section{A glicose diminuiu com o aumento} do peso das ovelhas (Figura 3), comportamento normal, uma vez que fêmeas adultas, com maior peso e boa condição corporal, tem menor quantidade de glicose circulante por não precisarem desse metabólito para ganho de peso.

Pela razão da menor quantidade

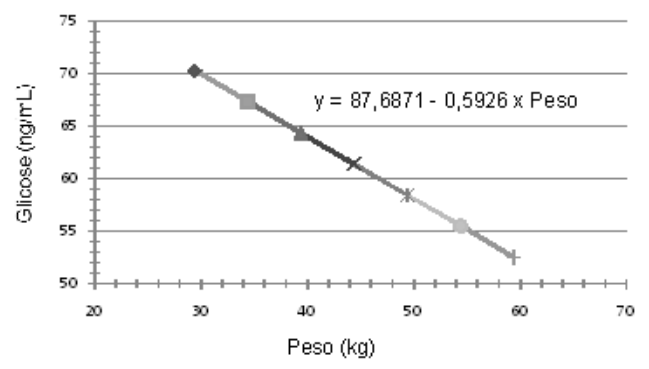

Figura 3 - Taxa média de glicose circulante $(\mathrm{ng} / \mathrm{mL})$ em função do peso de ovelhas Santa Inês, no momento da cobertura $(n=120)$.

de glicose circulante, as ovelhas mais pesadas apresentaram maior probabilidade de absorção embrionária, o que leva a recomendar-se a utilização de fêmeas ovinas, da raça Santa Inês, para cobertura ou como receptoras de embriões, com peso vivo que varia de 40 a $45 \mathrm{~kg}$.

A glicose diminuiu com o aumento da condição corporal (Figura 4). Tomando-se como referência a Figura 
1, pode-se afirmar que quanto maior a condição corporal menor será a taxa de glicose e maior a taxa de absorção

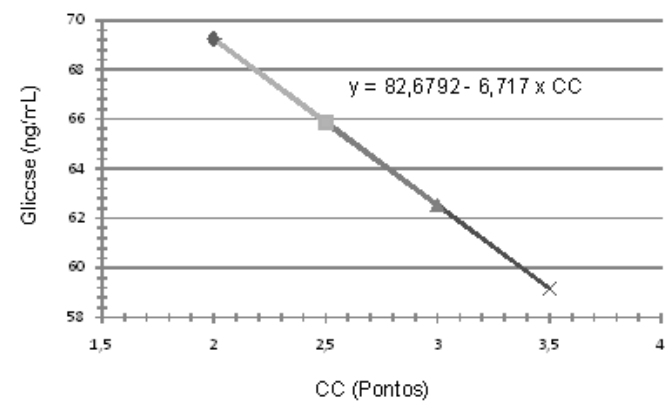

Figura 4 - Glicose circulante média ( $\mathrm{ng} / \mathrm{mL}$ ) em função da condição corporal a 5 (CC) de ovelhas Santa Inês, no dia da cobertura.

embrionária.

Entretanto, Rigolon et al. (1999), trabalhando com ovelhas Corriedale, não encontraram efeitos do nível de glicose plasmática na resposta superovulatória, e Santos et al. (2009) concluíram que $0,9 \%$ de suplementação energética por quilo de peso corporal melhorou o índice de prenhez de ovelhas acasaladas na primavera, comparadas com aquelas que receberam valores menores ou maiores de suplementação energética.

De acordo com López e Stumpf Júnior (2000), o aumento das concentrações de glicose plasmática são decorrentes da alta percentagem de ácido propiônico no rúmen e da hidrólise do amido no intestino delgado, com absorção direta da glicose. A concentração sanguínea de glicose, normalmente, diminui em resposta à alta concentração de insulina, que por sua vez está associada à diminuição da gliconeogênese hepática e o aumento do uso da glicose pelos tecidos periféricos (SANO et al., 1992).

Observa-se um ganho de peso linear das fêmeas ovinas, de 0 a 50 dias pós-cobertura, em função do aumento da energia da dieta, comportamento normal, uma vez que a dieta com menor energia foi suficiente para suprir as necessidades energéticas das ovelhas no terço inicial da gestação (Figura 5), demonstrando que o NRC (2007) superestima a exigência energética para esta fase.

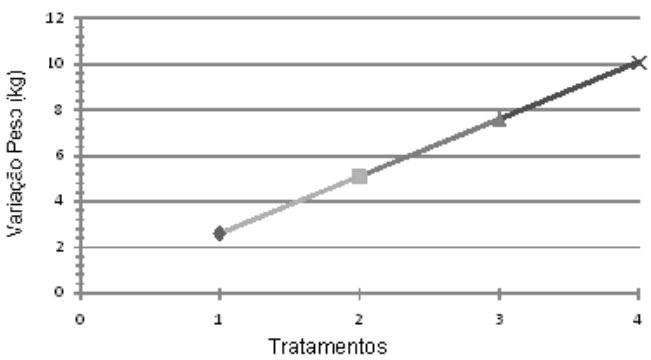

- Variação do peso médio das ovelhas, nos 50 dias após cobertura em função dos níveis de suplementaçã̃o ou restrição de energia.

Lea et al. (2006), analisando os efeitos da subnutrição em diferentes estágios da gestação de ovelhas, concluíram que os ovários de fêmeas nascidas de mães que tiveram restrições alimentares nos 30 primeiros dias de gestação terão menor número de células germinativas ovarianas, 0 que reduzirá o número de folículos primordiais nos ovários, causando, como consequência, subfertilidade.

\section{CONCLUSÃO}

No momento da cobertura das fêmeas, a taxa de glicose circulante é um dos fatores a serem observados, uma vez que animais que apresentaram maior taxa de glicose no dia da cobertura apresentaram menor percentagem de perdas embrionárias e, consequentemente, maior taxa de prenhez. Por não ter havido efeito dos níveis energéticos na alimentação das ovelhas, da cobertura até 50 dias póscobertura sobre a taxa de prenhez, recomenda-se o fornecimento de dieta com $59,68 \%$ de NDT ou $90 \%$ da energia de mantença recomendada. A condição corporal das fêmeas ovinas, no momento da cobertura, deve ser de três pontos, quando se verificou maior taxa de prenhez, diminuindo quando a CC variou 0,5 pontos para mais ou para 
menos. Além disto, orienta-se utilizar o flushing apenas em ovelhas com condição corporal entre 2 e 2,5 e a manutenção da oferta de energia a partir da CC 3, uma vez que as respostas causadas pelo efeito dinâmico negativo ou positivo podem ser prejudiciais.

\section{REFERÊNCIAS}

ARAÚJO, D.F.; SILVA, I.P. Valores de amilase, glicose, colesterol e triglicérides em soro de cabras em Mossoró, RN. Acta Veterinaria Brasilica, v.2, n.3, p.97-100, 2008.

ASHWORTH, C.J. Maternal and conceptus factors affecting histotrophic nutrition and survival of embryos. Livestock Production Science, v.44, n.2, p.99-105, 1995.

CEZAR, M.F.; SOUSA, W.H. Avaliação e utilização da condição corporal como ferramenta de melhoria da reprodução e produção de ovinos e caprinos de corte. In: REUNIÃO ANUAL DA SBZ, 43, 2006, João Pessoa. Anais... João Pessoa, Sociedade Brasileira de Zootecnia, 2006. p.541-565.

CORREIA NETO, J.; COSTA, A.N.; REIS, J.C. Parâmetros reprodutivos de ovelhas Santa Inês e suas cruzas com machos das raças Dorper e Somalis brasileira, obtidas por inseminação artificial. Ciência veterinária tropical, v.9, n.3, p.63-73, 2006.

EDEY, T.N. Nutrition and embryo survival in the ewe. Proceeding of the New Zealand Society of Animal Production, v.36, n.1, p.231-239, 1976.

GUNN, R.G.; MAXWELL, T.J. A note on the effect of direction of live weight change about the time mating on reproductive performance of Greyface ewes. Animal Production. v.48, n.2, p.471-474, 1989.

LEA, R.G.; ANDRADE, L.P.; RAE, M.T. et al. Effects of maternal undernutrition during early pregnancy on apoptosis regulators in the ovine fetal ovary. Reproduction, v.131, n.1, p.113-24, 2006.

LEESE, H.J. Quiet please, do not disturb: a hypothesis of embryo metabolism and viability. Bioessays, v.24, n.9, p.845-849, 2002.
LÓPEZ, J.; STUMPF JUNIOR, W. Influência do grão de sorgo como fonte de amido em ovinos alimentados com feno. Parâmetros Plasmáticos. Revista Brasileira de Zootecnia, v.29, n.4, p.1183-1190, 2000.

MENZIES, F.; BRYSON, D.; MALONE, F. Management of the breeding ewe at mating and in early pregnancy. In: Menzies, $\mathbf{F}$ et al. (Eds), Healthy sheep, healthy profits. Belfast: Crown Copyright, 1998, p.7-10.

NATIONAL RESEARCH COUNCIL. (NRC). Nutrient requirements of small ruminants: sheep, goats, cervids and new world camelids. Washington: The National Academies Press, 2007. 384p.

PARR, R.A.; CUMMING, I.A. Effects of maternal nutrition and plasma progesterone concentrations on survival and growth of the sheep embryo in early gestation. The Journal of Agricultural Science, v.98, n.1, p.39-46, 1982.

RAMIM, A-G.; SIAMAK, A-R.; MACALI, S-A. Evaluation on serum glucose, BHB, urea and cortisol concentrations in pregnant ewes.

Medycyna Weterinary, v.63, n.6, p.674-677, 2007.

RESENDE, K.T.; PEREIRA FILHO, J.M.; TRINDADE, I.A.C.M. et al. Exigências nutricionais de caprinos leiteiros. In: A produção animal na visão dos brasileiros. Piracicaba: FEALQ, 2001. p.484-496.

RIGOLON, L.P.; CAVALIERI, F.L.B.; SILVEIRA, $A$. Efeitos do nível de suplementação energética e protéica na resposta superovulatória de ovelhas da raça Corriedale. Iniciação Científica, CESUMAR, v.1, n.1, p.14-19, 1999.

RUBIO, J.M.; HALLFORD, D.M.; HAWKINS, $D$.E. Effect of glucose administration during the estrous cycle on serum hormone profiles, mRNA for steroidogenic enzymes, and breeding performance of ewes. Journal of Animal Science, v.75, n.3, p.775-780, 1997.

SANO, H.; MATSUNOBU, S.; ABE, T. et al. Combined effects of diet and cold exposure on insulin responsiveness to glucose and tissue responsiveness to insulin in sheep. Journal of Animal Scince, v.70, n.11, p.3514- 520, 1992.

SANTOS, G.M.G.; SILVA, K.C.F.; CASEMIRO, T. R. et al. Reproductive performance of ewes mated in the spring when given nutritional supplements to enhance energy levels. Animal Reproduction, v.6, n.2, p.422-427, 2009. 
SASA, A.; TESTON, D. C.; RODRIGUES, P. A. et al. Concentrações plasmáticas de progesterona em borregas lanadas e deslanadas no período de Abril a Novembro, no estado de São Paulo. Revista Brasileira de

Zootecnia, v.31, n.3, p.1150-1156, 2002.

SEIDEL, H.; NOVOTNÝ, J.; KOVÁC, G.

Selected Biochemical indices in sheep during pregnancy and after parturition. Bulletin of the Veterinary Institute in Pulawy, v.50, n.1, p.167-170, 2006.

SIMPLÍCIO, A.A.; FREITAS, V.J.F.; FONSECA, J. F. Biotécnicas da reprodução como técnicas de manejo reprodutivo em ovinos. Revista Brasileira de Reprodução Animal, v.31, n.2, p.234-246, 2007.

UNDERSANDER, D.J.; HOWARD, W.T.; SHAVER, R.D. Milk per acre spreadsheet for combining yield and quality into a single term. Journal Production Agriculture, v.6, n.2, p.231-235, 1993.

WILLIAMS, A.H.; CUMMING, I.A. Inverse relationship between concentrations of progesterone and nutrition in ewes. The Journal of Agricultural Science, v.98, n.3, p.517-522, 1982. 